\title{
Biology, Culture, and the Origins of Pet-Keeping
}

\author{
Harold A. Herzog ${ }^{1 *}$
}

\begin{abstract}
${ }^{1}$ Western Carolina University
*Corresponding author (Email: herzog@email.wcu.edu)

Citation - Herzog, H. (2014). Biology, culture, and the origins of pet-keeping. Animal Behavior and Cognition, 1(3), 296-308. doi: 10.12966/abc.08.06.2014
\end{abstract}

\begin{abstract}
Attachments between non-human animals of different species are surprisingly common in situations involving human agency (e.g., homes, zoos, and wildlife parks). However, cross-species animal friendships analogous to pet-keeping by humans are at least rare and possibly non-existent in nature. Why has pet-keeping evolved only in Homo sapiens? I review theories that explain pet-keeping either as an adaptation or an evolutionary by-product. I suggest that these explanations cannot account for the wide variation in the distribution and forms of pet-keeping across human societies and over historical time. Using fluctuations in the popularity of dog breeds in the United States, I show how shifts in choices of pets follow the rapid changes in preferences that characterize fashion cycles. I argue that while humans possess some innate traits that facilitate attachment to members of other species (e.g., parental urges, attraction to creatures with infantile features), pet-keeping is largely a product of social learning and imitation-based cultural evolution.
\end{abstract}

Keywords - Pet-keeping, Cultural transmission, Cultural evolution, Interspecies attachment, Adaptationism, Biophilia, Cross-species adoption

Are humans the only animal to keep pets, and if so, why? The public is fascinated by reports of attachments between non-human animals of different species (henceforth "animals"). This is not a new phenomenon. For example, a lion and lamb which had formed a special friendship were put on public display in London in 1654 (Thomas, 1984). Today, affectionate relationships between animal "odd couples" are among the most widely viewed of animal YouTube clips (Nelson \& Fijn, 2013). Natural history television specials depicting inter-species relationships have recently aired in the United States and in the United Kingdom, and books with titles such as Unlikely Friendships: 50 Remarkable Stories from the Animal Kingdom (Holland, 2011) have become bestsellers. Among the more famous cases of inter-specific friendships are the relationships between Koko, a sign-language trained gorilla, and a kitten (Patterson \& Cohn, 1985); Mzee, an orphaned hippopotamus in Kenya, and a 160-year-old giant tortoise (Hatkoff et al., 2006); and Tarra, an Asian elephant, and a dog named Bella (Buckley, 2009).

A few systematic studies have also demonstrated that animals have the capacity to become attached to members of other species. In an early experiment, Kuo (1930) found that six of eighteen kittens raised with rats became strongly attached to their rodent cage-mates, and wrote, "Indeed, if cats have an instinct of love, certain of my kittens have 'shown' it in their response to rats" (p. 26). Mason and Kenny (1974) paired juvenile rhesus monkeys with adult dogs. Within a few hours after being introduced, the dogs and monkeys showed clear signs of attachment. After several months living together, each monkey was given a choice between interacting with the dog it was paired with, a strange dog, or another monkey. In nearly all cases, the monkeys chose to associate with the dog they had become attached to.

The problem, however, is that all of these cases of long-term inter-specific attachments have occurred in situations involving significant human intervention such as households, zoos, and wildlife parks in which the animals were provisioned. In some well-known cases, the cross-species interactions 
were facilitated by professional animal trainers (see, for example, Antle, 2011). That being said, the existence of inter-specific odd couples demonstrates that non-human animals are capable of becoming attached to members of other species. They do not, however, provide convincing evidence that animals maintain long-term interspecific relationships in nature analogous to human pet-keeping.

There is one possible documented exception to the notion that pet-keeping is a uniquely human phenomenon. In 2004, researchers in Brazil discovered a group of capuchin monkeys that had adopted an infant marmoset which the researchers named Fortunata, and the marmoset-capuchin interactions were observed systematically over the next 14 months (Izar et al., 2006). The marmoset was socially integrated into the capuchin group, and two females in succession served as the marmoset's primary caretakers. The capuchins carried the marmoset around, played with it, and frequently fed the much smaller monkey. This is apparently the only published report of interspecific adoption in free-ranging non-human primates. While the researchers referred to this capuchin-marmoset relationship as cross-genus adoption rather than pet-keeping, it bears obvious similarities the relationships between people and pets. Even in this case, however, the environmental situation was not completely natural; while not captives, the animals were living in a large biological reserve where they were provisioned with food daily as part of a project to encourage eco-tourism. Nonetheless, this instance of inter-specific adoption illustrates the fact that some animal species have both the emotional capacity to become attached to juvenile members of other species and the ability to feed and protect them.

An obvious place to look for human-like pet-keeping in completely natural environments would be among chimpanzees, our closest primate relative. Chimpanzees occasionally capture small animals with which they sometimes appear to "play." Inevitably, however, these interactions do not turn out well for the putative pet. Boesch and Boesch (1989), for instance, observed a group of chimpanzees capture a young blue duiker. Four young chimpanzees proceeded to play with the screaming antelope, which within 15 minutes died from rough handling. Yet, the chimpanzees continued to play with the duiker corpse for another half hour. Hirata, Yamakoshi, Fujita, Ohashi and Matsuzawa (2001) reported two incidents in which wild chimpanzees captured tree hyraxes. In the first case, the hyrax was killed when it was assaulted with a sapling, and in the second case, the chimps swung the hyrax around, smashed it on the ground, and then beat it to death. An adult female subsequently carried the dead hyrax for over an hour, treating it like a doll and grooming the corpse. In neither case was the hyrax eaten. At her field site in Fangoli, Senegal, Pruetz observed several incidents in which chimpanzees captured genets, again toying and playing with them roughly until the genets died (J. Pruetz, personal communication, 2013). In all of these cases, the only similarity with the human-pet relationship is that the chimpanzees failed to eat the captured animals. Indeed, Pruetz does not know of any cases in which a wild chimpanzee has been reported to adopt a juvenile or adult of another species.

In their review of theories of the evolution of human-pet keeping, Serpell and Paul (2011) stated that cross-species adoptions analogous to pet-keeping are common in animals in both captive and wild situations. However, aside from the case of Fortunata, their only reference is to a website which offers photographs of animal odd couples, all involving captive situations or domesticated species ${ }^{1}$. Hence, while close attachments between animals of different species are not uncommon in situations involving human intervention, I have found no scientific research reports of interspecific attachments in nature analogous to pet-keeping. In her review of this literature, Shipman (2010) came to the same conclusion.

\section{Evolutionary Theories of Pet Keeping}

Serpell (1989) succinctly defined pets as animals we live with that have no apparent function. People choose to live with non-working animals for a variety of reasons. Among these are status, aesthetic appeal, and simply personal fascination with a type of animal. Yet the psychology underlying pet-keeping is different from collecting ornamental Japanese koi because of their decorative appearance. Thus I would add that relationships between pets and keepers are typically characterized by affection and

\footnotetext{
${ }^{1}$ (http://daughterearth.com/blog/2008/12/cross-species-adoptions/)
} 
are relatively long-lasting as opposed to transient (e.g., a single play episode). In addition, as seen in the case of Fortunata, these interspecific relationships usually include a care-taking component. But devoting time, energy, and resources to animal companions which have no apparent function poses an obvious evolutionary problem as it appears to be a form of altruism that cannot be explained by kin selection or reciprocal altruism.

Evolutionary explanations of pet-keeping fall into two categories (Serpell \& Paul, 2011). The first are hypotheses which hold that pet-keeping is an evolved adaptation that enhances the fitness of pet owners. Of particular importance is idea that pets have a beneficial impact on human health via social buffering. Fueled by media reports and books such as The Healing Power of Pets: Harnessing the Amazing Ability of Pets to Make and Keep People Happy and Healthy (Becker, 2003), it is now widely believed that pets enhance their owner's health, psychological well-being, and longevity. The first empirical evidence of what Allen (2003) referred to as the "pet effect" was a study which found that heart attack victims who owned pets had higher one-year survival rates than non-pet owners (Friedmann, Katcher, Lynch, \& Thomas, 1980). Subsequent studies have reported, for example, that interacting with pets decreases stress and lowers blood pressure, that pet owners have higher self-esteem and more positive moods, greater life satisfaction, lower levels of loneliness, and they make fewer doctor visits and exercise more (for reviews see Headey \& Grabka, 2011; Levine et al., 2013; Wells, 2009).

Studies on the impact of pets on human health, however, have produced inconsistent findings (Herzog, 2011). In some epidemiological studies, pet owners have been found to be more likely than non-pet owners to suffer from depression, anxiety, fatigue, panic attacks, insomnia, and generally poor health (Koivusilta \& Ojanlatva, 2006; Müllersdorf, Granström, Sahlqvist, \& Tillgren, 2010; Parslow, Jorm, Christensen, \& Rogers, 2005). Hawkley and Cacioppo (2010) reported that adults with close human friends had better psychological well-being as indicated by their levels of self-esteem, loneliness, sense of isolation, depression, and life satisfaction. In contrast, pet ownership had no relationship with any of these variables. Further, there is no evidence that pet owners live longer than non-pet owners (Gillum \& Obisesan, 2010). Thus, while some studies have found that living with pets provides medical and psychological benefits to their owners, the existence of a general beneficial "pet effect" on human health and happiness is not a well-established fact but a hypothesis for which there is some support.

On the other hand, there are clear health risks of living with pets. In the United States, four and a half million people each year are bitten by dogs, and several dozen individuals are killed by them (Patronek, Slater, \& Marder, 2010; Sacks, Kresnow, \& Houston, 1996). Over 85,000 people annually suffer serious injuries from tripping over their pets (Center for Disease Control, 2009), and humans can contract a host of zoonotic diseases from companion animals. Among these are salmonella, roundworms, skin mites, Lyme disease, giardia, leptospirosis, toxoplasmosis, and E. coli (Pickering, Marano, Bocchini, \& Angulo, 2008; Torrey, \& Yolken, 2005).

Another adaptationist theory of the evolution of pet keeping is that caring for an animal functions as an honest signal of the parental abilities of the owner (Serpell \& Paul, 2011). No studies have examined the impact of living with pets or loving animals on reproductive fitness. Several studies, however, have found that women are attracted to men with pets. Gueguen and Ciccotti (2008) had a handsome male confederate approach 240 female strangers at a public mall. He asked each of the women if they would be interested in meeting later for a drink, and if so, to give him their phone number. On half of these approaches he was alone and on the other half he was accompanied by a medium sized mixedbreed dog. The presence of the dog tripled the number of women who gave him their phone number, from $10 \%$ to $30 \%$. In a recent Israeli study (Tifferet, Kruger, Lar-Lev, \& Zeller, 2013), women of reproductive age rated the relative appeal of "cads" (men who were described as highly competitive and who invested their efforts primarily in mating rather than parenting) and "dads" (men who were described as kind, romantic, nurturing, and who invested more in parenting.) The subjects read scenarios in which both cads and dads varied by whether they were described as dog owners. Pet ownership increased overall attractiveness of the subjects, and it was particularly important in increasing the desirability of cads for long-term relationships. 
The third adaptionist hypothesis for the evolution of pet-keeping is that caring for animals facilitates the development of empathy and parental skills that could be applied to the care of human infants and children (Bradshaw \& Paul, 2010). Studies have found correlations between pet ownership and empathy and social commitment in children (e.g., Daly \& Morton, 2003; Mueller, 2014; Taylor \& Signal, 2005). And the spread of pets into the middle class in the $19^{\text {th }}$ century was partially motivated by the notion that caring for animals encouraged nurturance and responsibility in children (Grier, 1999). While the idea that pet-ownership increases reproductive fitness because it encourages empathy and parenting skill is reasonable, there is no direct support for this hypothesis.

Traits such as nipples on males and the navel are not adaptations per se, but are byproducts of traits that are linked to reproductive success (Buss, Haselton, Shackelford, Bleske, \& Wakefield, 1998). Some researchers argue that pet-keeping is a byproduct of evolved tendencies linked to the care of human offspring (e.g., Archer \& Monton, 2011; Bradshaw \& Paul, 2010; Gould, 1979). Neurophysiological and behavioral evidence supports the idea that humans are naturally attracted to creatures with infantile facial characteristics such as big eyes, large crania, and soft, round facial features (e.g., Archer \& Monton, 2011; Borgi \& Cirulli, 2013; Glocker et al., 2009; Little, 2012). Indeed, a recent study in real-world selection situation (animal shelters) found that dogs with juvenile (paedomorphic) facial features were more likely to be adopted than dogs with less infantile characteristics (Waller et al., 2013).

Archer $(1997 ; 2011)$ takes the non-adaptionist view of the evolution of pet-keeping a step further. $\mathrm{He}$ argues that devoting resources to companion animals is actually a maladaptive consequence of misfiring of evolved parental urges. Archer compares pet-keeping to avian brood-parasitism in which a female cowbird, for example, will lay an egg in the nest of another species. The duped host then feeds and cares for the unrelated nestling.

Serpell (2003) makes the case that pet-keeping arose as the consequence of anthropomorphism, the tendency to project human mental states onto non-human species. Though its origins are unclear, Mithen (1996) theorized that anthropomorphism was the manifestation of a form of cognitive fluidity that first evolved in Homo sapiens about 40,000 years ago. Anthropomorphism would have been a mixed bag for our ancestors. On the one hand, a hunter who could project him or herself into the minds of their prey would be more successful. But on the other, this same ability would make early hunters empathize with the animals they were trying to kill. Thus anthropomorphism led to both guilt and the evolution of petkeeping (Serpell, 1996.) Studies do link anthropomorphism and pet-keeping. For instance, when made lonely by an experimental manipulation, subjects were more inclined to think anthropomorphically about their pets (Epley, Akalis, Waytz, \& Cacioppo, 2008). While anthropomorphism appears to be a deeply rooted aspect of human cognition (Guthrie, 1995), the degree that people project human mental states on other species is affected by culture as well (Epley, Waytz, \& Cacioppo, 2007).

\section{Problems with Evolutionary Theories of Pet-Keeping}

There is little doubt that the forces of selection, particularly as related to the rearing of offspring, have predisposed humans and some animals to become attached to members of other species under the right circumstances. For the reasons outlined below, however, I believe it is unlikely that biological forces related to natural selection provide an adequate explanation of human pet-keeping.

\section{The Occurrence and Forms of Pet-Keeping Varies Widely Over Human Cultures}

It is sometimes claimed that pet-keeping is wide-spread or even universal among human cultures (e.g., Serpell \& Paul, 2011; Shipman, 2010). With about half of all households worldwide including an animal (Westgarth et al., 2010), there is little doubt that pet-keeping is presently common in many, if not most, human societies. An examination of the anthropological literature, however, suggests that frequency and forms of pet-keeping and even existence of the concept of "pet" have varied widely across human societies. 
Unlike human universal characteristics such as language, art and prohibitions between sex with first degree relatives, pets as we think of them today do not exist in many cultures. The Kiembu people of Kenya live with dogs which they keep to ward off animals and threaten strangers. But the Kiembu do not consider these animals as companions. They never let them inside their homes or play with them. Indeed, the Kiembu language does not contain a word that corresponds to "pet" (Herzog, 2010). Jared Diamond (1993) noted that while he often observed the keeping of captured wild animals among tribal peoples in Amazonia, this practice was very rare in New Guinea. New Guineans regularly captured animals, but these creatures were often treated with indifference or abject cruelty. For example, the legs of animals destined to be eaten later in the day would be broken to keep them from escaping. And for amusement, captive bats would be tethered by a string and repeatedly lowered into the burning embers of a fire.

In addition to the frequency of pet-keeping, the styles of human-pet relationships vary among cultures. The range of animals kept as pets in different parts of the world is extraordinary (Serpell, 1987). In the Amazon Basin, different tribal groups adopt different companion animals: the Matse favor sloths, the Txicao prefer capybaras, and the Ache go for coatis (Erikson, 2000). Gray and Young (2011) conducted the only systematic review of cross-cultural patterns of pet-keeping by analyzing a probability sample of 60 societies drawn from the Human Area Relations Files. Species kept as pets in these societies included caimans, ostriches, tortoises, pigs, monkeys, bears, and bats. Dogs were the most common pet species, though they were treated quite differently in different societies. Humans lived with dogs in 53 of the 60 cultures but were considered pets in only 22 of them. Even in these societies, however, pet dogs were maintained primarily for utilitarian purposes such as hunting, defense against people or predators, herding and carrying, and waste removal; they were not afforded the status of friend or family member. Dogs were only adequately fed and allowed inside human homes in seven of the cultures. In many of the societies, dogs were mistreated. They were regularly beaten in 13 of the cultures, and in 11 societies, were sometimes intentionally killed. Most surprisingly, dogs were played with in only three of the 60 cultures. Gray and Young concluded that the affection and resources lavished upon pets in the United States and Europe today is a cultural anomaly.

In addition to cross-cultural differences, attitudes towards pets sometimes vary considerably between subgroups within a society. In Tanzania, Christian households are twice as likely to include a dog as Muslim homes (Knobel, Laurenson, Kazwala, Boden, \& Cleaveland, 2008). In the United States, rates of pet ownership are low among traditional Orthodox Jews, though they may be higher among modern Orthodox Jews (A. Glicksman, personal communication, January 25, 2014).

\section{Attitudes Toward Pets Change, Sometimes Quickly}

Another problem with the notion that love for animals in humans is an evolved functional adaptation is that attitudes toward pets can shift markedly over time. Presently about two-thirds of households in the United States and half of homes in the United Kingdom contain a pet. Yet, pet-keeping among ordinary people in these countries only emerged within the last 200 years (Ritvo, 1987). Google Lab's NgramViewer (https://books.google.com/ngrams/) is a graphing tool used to study social change through the analysis of relative frequencies of words in five million books $(N=300$ billion words) digitized by Google (Michel et al., 2011). Figure 1 shows shifts in frequency of the term "pet" in books published in the United States between 1800 and 2000. After holding steady for over a century, the frequency of the word "pet" shot up over 450\% between 1947 and 2000. This sudden and dramatic increase clearly reflects a major change in the importance of companion animals in the lives of Americans in the post-World War II years. 


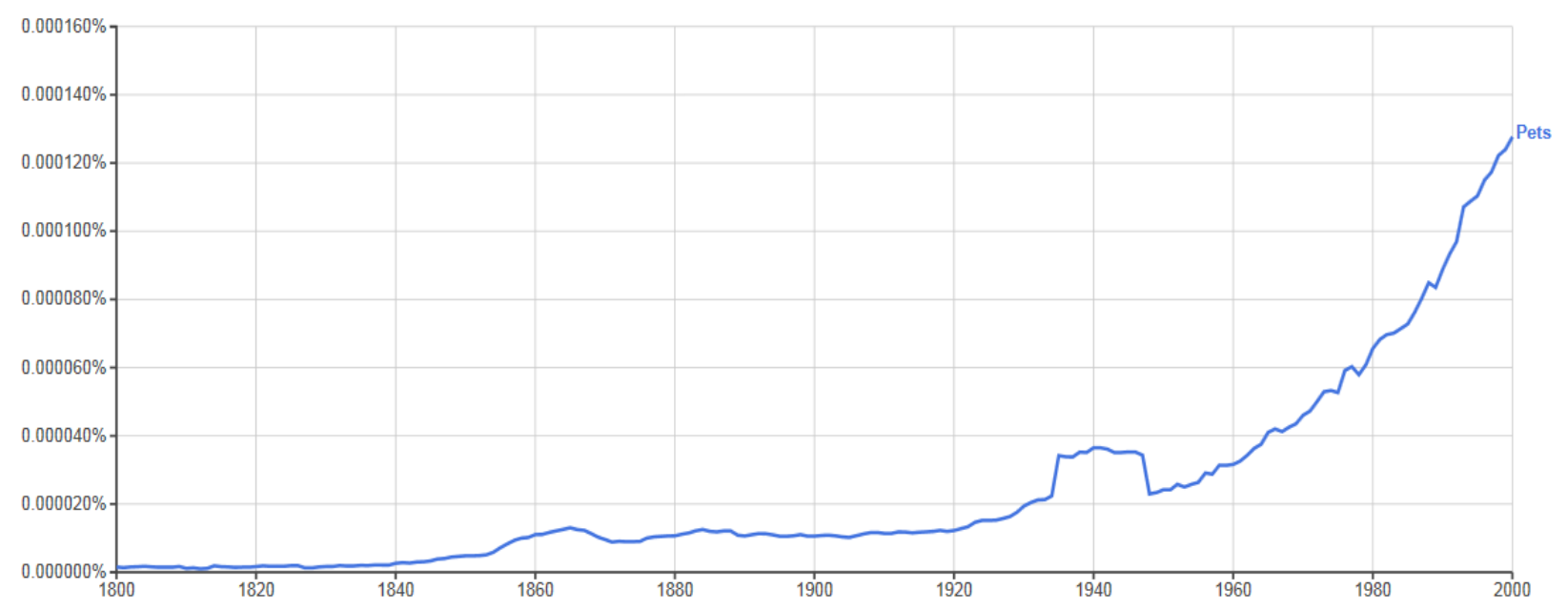

Figure 1. Changes in the relative frequency of the word "pet" in books printed in the United States between 1800 and 2000.

The human-cat relationship provides another example of changes in attitudes toward pets (Bradshaw, 2013). Evidence that people kept cats as pets dates to $4000 \mathrm{BC}$ in Egypt when images of cats in domestic scenes began to appear on temple walls. By $3500 \mathrm{BC}$, cats had become objects of worship, and as a result, became the objects of sacrifice. Thus while Egyptian cats were beloved as pets, they were also produced by the millions solely to be mummified. In Europe, things took a turn for the worse for cats in the $13^{\text {th }}$ century when they were linked with witchcraft by the Catholic Church. Thus ensued a 300 year campaign of systematic feline torture and genocide, the goal of which was to exterminate cats entirely. Cats began to be considered in a more positive light in the $18^{\text {th }}$ century, and their image was completely rehabilitated when Queen Victoria became a cat lover. Today, more cats than dogs live in American homes.

Fads for different types of pets can sweep across a culture. Monkeys were popular in Europe in the $13^{\text {th }}$ century. As pet-keeping spread from the aristocracy to the middle class in the $16^{\text {th }}$ century, popular pets included tortoises, squirrels, otters, and hedgehogs (Thomas, 1984). In the $18^{\text {th }}$ century, mice and other "pocket pets" became popular as did bats and toads. At the turn of the $20^{\text {th }}$ century, the most common pets among the American middle class were caged song birds, a trend that in the 1920s was followed by a craze for aquarium fish (Grier, 2006). A "beetle boom" spread through Japan in the 1960s when department stores began selling giant stag and rhinoceros beetles and paraphernalia for their care and housing (Laurent, 2000). Over the last five decades, short-lived enthusiasms for creatures such as baby turtles, horned toads, miniature pigs, and even "pet rocks" have swept through American culture.

Pet-keeping would seem to be an obvious manifestation of E. O. Wilson's concept of biophilia, which he originally defined as the "innate tendency to focus on life and life-like processes." (1984, p. 1). Cultural differences and historical changes in patterns of pet-keeping, however, do not support the idea that love for animals is a hard-wired human trait. Indeed, Wilson himself changed his views on the innateness of biophilia, and later wrote, "Biophilia is not a single instinct but a complex of learning rules that can be teased apart and analyzed individually" (Wilson, 1993, p. 31).

\section{Pet Popularity as a Model of Cultural Change: The Case of Dog Breeds}

Wilson (1993) suggests that biophilia reflects aspects of social learning which can be subjected to empirical analysis. Models borrowed from quantitative genetics have been found useful in the study of cultural evolution and transmission (e.g., Mesoudi, 2011; Richerson \& Boyd, 2008). In recent years, social scientists have used shifts in the popularity of cultural variants such as baby names, web page hits, word frequencies in books, and top 40 songs to tease apart factors that impel large-scale social change 
(e.g., Acerbi, Lampos, Garnett, \& Bentley, 2013; Bentley, Lipo, Herzog, \& Hahn, 2007; Hahn \& Bentley, 2003; Lieberson, 2000). Over the past decade, my colleagues and I have examined factors that affect changes in the preferences for of types of pets, specifically, breeds of dogs. This body of research illustrates the importance of cultural transmission in human-animal relationships.

Founded in 1884, the American Kennel Club (AKC) maintains the world's largest registry of pedigreed dogs. Interest in purebreds grew rapidly in the United States in the years following World War II, and between 1944 and 1972, there was a 20-fold increase in the per capita number of annual AKC puppy registrations.

In 2002, the AKC provided me with the number of puppy registrations for each AKC recognized breed dating back to 1946 (subsequently backdated to 1927 and updated to 2005). This uniquely large and complete data set offers a model system for studying shifts in the preferences of Americans for types of pets. Note that AKC registrations do not perfectly reflect the likes and dislikes of American dog lovers. First, while 54\% of dogs in the United States are purebreds (American Veterinary Medical Association, 2012), many owners of purebreds do not register their pets. Second, some popular breeds such as the American pit bull terrier are not recognized by the AKC. Third, a few popular breeds have only recently been recognized by the $\mathrm{AKC}$ and, as a result, have misleadingly low registration numbers. Finally, since the mid-1990s, AKC registrations have fallen sharply, and these data thus may be less representative of breed popularity than in previous years. Despite these caveats, the size (52 million puppy registrations representing 160 breeds) and completeness of this data set make it useful model system for studying the dynamics of rapid cultural evolution. Below are summaries of our major findings.

Socially transmitted preferences in forms of culture such as baby names, hit songs, and web page hits typically conform to power law distributions in which most choices are concentrated among relatively few of the most popular variants (Hahn \& Bentley, 2003). Because of their extreme right skew, power law distributions are also referred to as "long-tailed" (see Bentley, Ormerod, \& Batty, 2011). Like many forms of popular culture, our preferences for types of dogs fit a power law distribution (Herzog, 2006; Herzog, Bentley, \& Hahn, 2004). In 2003, for example, 64\% of new AKC registrations $(584,041$ dogs) went to the top 15 breeds, while the bottom 15 breeds accounted for only $0.1 \%$ of registrations $(1,077$ dogs). Differences between the most popular and least popular breeds are enormous. In 1967, there were roughly 30,000 times more Poodle registrations $(N=255,862)$ than Clumber Spaniel registrations $(N=9)$.

Shifts in breed popularity can occur rapidly (Herzog, 2006). Annual Irish Setter registrations held steady at between 2,000 and 3,000 a year from the 1940s until the early 1960s when registrations began to rise at an accelerating rate. Between 1961 and 1974, Irish Setter registrations jumped 25 fold, from 2,526 to 61,549 . Then registrations plummeted, and by 1984 , they had dropped to $7 \%$ of their peak. Similar dramatic booms and busts have occurred in other breeds such as Dalmatians, Great Danes, Old English Sheep Dogs, and Rottweilers. From start of the booms to the end of the busts, these cycles lasted, on average 25 years, during which time annual registrations increased by nearly 3,500\% and then dropped equally rapidly.

Pronounced booms and busts, however, are the exception rather than the rule. We found that most fluctuations in breed popularity can be explained by a random drift model which assumes that cultural evolution is process in which people unconsciously copy the choices of other people (Herzog, Bentley, \& Hahn, 2004). Originally derived from the neutral theory of molecular evolution, random drift has been shown to be applicable to forms of culture ranging from baby names to Neolithic pottery styles (Bentley, Hahn, \& Shennan, 2004; Bentley et al., 2011).

Rapid changes in cultural preferences can be propelled by both external factors such as advertising and by internal factors such as a tendency for early adopters of a new variant to grow bored and seek fresher styles (Lieberson, 2000). As evidence of the operation of internal factors on changes in breed popularity, Bentley et al. (2006), for example, found that dog popularity cycles were remarkably similar to regularities in shifts in preferences for pop songs and baby names. Berger and LeMens (2009) discovered that the more rapidly a baby name becomes popular, the more rapidly it is subsequently abandoned. This "what goes up; goes down" internal principle of cultural change also applies to dog breed popularity. Among 55 breeds with distinct peaks in popularity between 1927 and 2005, the more 
rapidly puppy registrations increased, the more rapidly their popularity declined (Acerbi, Ghirlanda, \& Enquist, 2012).

Media exposure is an important external factor that can impel cultural change. These effects can be subtle. Berger, Bradlow, Braunstein, and Zang (2012), for example, found that media coverage of particularly destructive hurricanes resulted in an increase in the popularity of names with similar phonemes (e.g., an increase in the number of girls named Katie following Hurricane Katrina). We used the AKC puppy registrations to examine the impact of movies on changes in preferences for types of pets (Ghirlanda, Acerbi, \& Herzog, in press). The classic example is the Disney movie 101 Dalmatians. In the eight years following the 1985 re-release of the film, the annual number of new Dalmatian registrations increased from 8,170 puppies to 42,816 puppies. An even more dramatic example is the 100 -fold increase in Old English Sheepdog registrations following the 1959 Disney movie, The Shaggy Dog. To analyze the effects of movies on breed popularity, we examined the impact of movies featuring dogs released between 1926 and 1995 on puppy registrations. For the ten most influential dog films, movie-associated changes in registrations meant that 800,000 more puppies were registered with the $\mathrm{AKC}$ in the 10 years after the movie releases than would have been predicted from pre-release trends. Further, first day ticket sales of movies were significantly correlated with increases in breed popularity even 10 years later.

Not all media exposure, however, produces an increase in breed popularity. The well-known Taco Bell television ad campaign that ran between 1997 and 2000 featuring a Spanish-speaking Chihuahua named Gidget did not produce an increase in Chihuahua registrations. And, contrary to conventional wisdom, winning Best in Show at the prestigious Westminster Dog Show usually does not result in a substantial increase in new registrations of the winning breed (Herzog \& Elias, 2004).

Cultural variants such as smart phones and pop top beer cans become popular because they are objectively better than the product or style they replace. But some shifts in cultural preferences seem completely arbitrary (e.g., the baby name "Sophie" versus "Jenifer"). Using AKC puppy registrations, we recently examined the relationship between popularity and the "quality" of 80 dog breeds $(n=8,645$ individual dogs) as reflected in the frequency of breed-characteristic behavioral and health problems (Ghirlanda, Acerbi, Herzog, \& Serpell, 2013). We obtained indices of breed differences in behavior problems using the Canine Behavioral Assessment and Research Questionnaire (C-BARQ), a database maintained by the University of Pennsylvania Veterinary School. C-BARQ scores were on based on owner-reported evaluations of their dog's behavior and temperament on 14 variables (e.g., owner and stranger-directed aggression, fear, dog rivalry, and chasing) (Hsu \& Serpell, 2003). Our measures of health status were the number of genetic disorders the breeds were susceptible to and each breed's average longevity.

If people pick their pets on rational assessments of qualities such as good temperaments and low incidence of genetic disorders, breed popularity should be negatively correlated with rates of behaviors such as aggression and the frequencies of genetic disorders and longevity. This was not the case. The average correlations with problem behaviors were 0.06 for overall popularity, 0.02 for rates of increase in popularity, and 0.01 for rates of decrease in popularity. Similarly, correlations between longevity and popularity were not significant. There was, however, a significant positive correlation between the number of genetic diseases a breed was susceptible to and the number of puppy registrations $(\mathrm{r}=0.58)$. That is, popular breeds tended to have more rather than fewer genetic problems. On the whole, breeds with more desirable behaviors, greater longevity, and fewer inherited genetic disorders did not become more popular than other breeds. In short, cultural shifts in types of pets largely reflect ephemeral changes in fashion rather than selection for functional traits.

\section{Pet-Keeping and Gene-Culture Interactions}

The influence of social transmission on preferences for types of dogs sheds light on the question why humans, and only humans, keep pets. For several reasons, I have argued that it is unlikely that love for animals is a species-specific domain of human nature which evolved as a functional adaptation or as a by-product of selection for traits such as parental behavior or anthropomorphic thinking. First, there is no 
evidence linking attachment to companion animals with increased reproductive potential. More importantly, the great variation in the distribution and forms of our relationships with animals across cultures and over historical time argues against the idea that love for pets is an innate facet of human nature. Finally, shifts in the popularity of dog breeds indicate that cultural evolution can create the desire to live with specific types of animals.

Humans, however, are not blank slates when it comes to our interactions with other species. Infants show differential responses to animals such as snakes and spiders (Lobue \& Deloache, 2010; LoBue, 2010) and, given a choice, young children prefer to play with live animals rather than toys (LoBue et al., 2013). It is also likely that humans have evolved domain-specific perceptual systems specialized for the detection of animal movement (New, Cosmidis, \& Tooby, 2007). Further, we are among the most social of species, and our attachments to other species are rooted in neuro-hormonal mechanisms that evolved to facilitate social relationships with other humans. For example, some studies have found that interacting with pets stimulates the release of oxytocin, a hormone that promotes in social bonding (e.g., Beetz, Uvnäs-Moberg, Julius, \& Kotrschal, 2012).

In addition, people are predisposed to form social relationships with some species of animals rather than others. It is not an accident that more dogs live in human societies than do turtles or bats. The progenitors of dogs probably began their path from wolf to pampered pet through self-domestication via natural selection for tameness (Coppinger \& Coppinger, 2002). Hare and Tomasello (2005) argue that through convergent evolution, dogs came to possess human-like social skills which opened up special lines of communication between Homo sapiens and Canis familiarus. Indeed, polymorphisms in the canine OXTR gene suggests that oxytocin mediates human-directed behavior in dogs, just as it is does in pet-directed behavior in their owners (Kis et al., 2014). Similarly, cultures differ in the degree that they are open to the transmission of pet-keeping memes. For example, dogs are rarely kept as pets in Arab countries because they are considered to be unclean in the Koran (Al-Fayez, Awadalla, Templer, \& Arikawa, 2003). And the popularity of insect pets among Japanese children follows from the traditional Japanese aesthetic of miniaturization of nature (Watanabe, 1974).

Pet-keeping, it seems, exemplifies the types of gene-culture interactions that shape many aspects of human behavior. An example was suggested by Elizabeth Paul (personal communication, February 12, 2014) who made an analogy between love of pets and the desire to eat cheesecake ${ }^{2}$. Cheesecake, like petkeeping, is found only in some cultures. And preferences for specific varieties of cheesecake undergo shifts which are probably attributable to random drift. The pleasure we derive from eating cheesecake, however, is rooted in evolved taste preferences for sweets and fats that served our ancestors well. And, under human influence (e.g., an open garbage can), some animals will come to relish cheesecake, just as some animals form unusual interspecific attachments under human influence.

In short, the emergence of pet-keeping in our species involved a mix of innate predispositions and social learning. Cultural and historical differences in frequency and forms of pet-keeping indicate that biologically-based theories, in themselves, cannot adequately explain the evolution of pet-keeping. Traits such as parental care and anthropomorphism were necessary but not sufficient for the emergence of petkeeping. Pet-keeping was made possible by the emergence of social transmission as a dominant force in human evolution.

\section{References}

Acerbi, A., Ghirlanda, S., \& Enquist, M. (2012). The logic of fashion cycles. PloS ONE, 7, e32541.

Acerbi, A., Lampos, V., Garnett, P., \& Bentley, R. A. (2013). The expression of emotions in 20th century books. PloS ONE, 8, e59030.

Al-Fayez, G., Awadalla, A., Templer, D. I., \& Arikawa, H. (2003). Companion animal attitude and its family pattern in Kuwait. Society and Animals, 11, 17-28.

Allen, K. (2003). Are pets a healthy pleasure? The influence of pets on blood pressure. Current Directions in Psychological Science, 12, 236-239.

${ }^{2}$ Pinker (1997) also used the analogy with cheesecake when arguing that music is a non-adaptive evolutionary byproduct. 
American Veterinary Medical Association (2012). U.S. pet ownership demographics sourcebook. Shaumburg, IL: American Veterinary Medical Association.

Antle, B. (2011). Suryia and Roscoe: The true story of an unlikely friendship. New York: Henry Holt.

Archer, J. (1997). Why do people love their pets? Evolution and Human Behavior, 18, 237-259.

Archer, J. (2011). Pet keeping: A case study in maladaptive behavior. In C. A. Salmon and T. K. Shackelford (Eds.) The Oxford handbook of evolutionary family psychology (pp. 281-296). New York: Oxford University Press.

Archer, J., \& Monton, S. (2011). Preferences for infant facial features in pet dogs and cats. Ethology, 117, 217-226.

Becker, M. (2003). The healing power of pets: Harnessing the amazing ability of pets to make and keep people happy and healthy. New York: Hyperion.

Bentley, R. A., Hahn, M. W., \& Shennan, S. J. (2004). Random drift and culture change. Proceedings of the Royal Society B - Biological Sciences, 271, 1443-1450

Bentley, R. A., Lipo, C. P., Herzog, H. A., \& Hahn, M. W. (2007). Regular rates of popular culture change reflect random copying. Evolution and Human Behavior, 28, 151-158.

Bentley, R. A., Ormerod, P., \& Batty, M. (2011). Evolving social influence in large populations. Behavioral Ecology and Sociobiology, 65, 537-546.

Berger, J., Bradlow, E. T., Braunstein, A., \& Zhang, Y. (2012). From Karen to Katie using baby names to understand cultural evolution. Psychological Science, 23(, 1067-1073.

Berger, J., \& Le Mens, G. (2009). How adoption speed affects the abandonment of cultural tastes. Proceedings of the National Academy of Sciences, 106, 8146-8150.

Borgi, M., \& Cirulli, F. (2013). Children's preferences for infantile features in dogs and cats. Children, 1, 1-15.

Boesch, C., \& Boesch, H. (1989). Hunting behavior of wild chimpanzees in the Tai National Park. American Journal of Physical Anthropology, 78, 547-573.

Bradshaw, J. (2013). Cat sense: How the new feline science can make you a better friend to your pet. New York: Basic Books.

Bradshaw, J., \& Paul, E. (2010). Could empathy for animals have been an adaptation in the evolution of Homo sapiens? Animal Welfare, 19(Supplement 1), 107-112.

Beetz, A., Uvnäs-Moberg, K., Julius, H., \& Kotrschal, K. (2012). Psychosocial and psychophysiological effects of human-animal interactions: The possible role of oxytocin. Frontiers in Psychology, 3, 1-15.

Buckley, C. (2009). Tarra \& Bella: The elephant and dog who became best friends. New York: Putnam.

Buss, D. M., Haselton, M. G., Shackelford, T. K., Bleske, A. L., \& Wakefield, J. C. (1998). Adaptations, exaptations, and spandrels. American Psychologist, 53, 533.

Center for Disease Control. (2009). Nonfatal fall-related injuries associated with dogs and cats. Morbidity and Mortality Weekly Report. Retrieved from http://www.cdc.gov/mmwr/preview/mmwrhtml/mm5811a1.htm

Coppinger, R., \& Coppinger, L. (2002). Dogs: A new understanding of canine origin, behavior, and evolution. Chicago, IL: University of Chicago Press.

Daly, B., \& Morton, L. (2003). Children with pets do not show higher empathy: A challenge to current views. Anthrozoös, 16, 298-314.

Diamond, J. (1993). New Guineans and their natural world. In S. R. Kellert \& E. O. Wilson (Eds.) The biophilia hypothesis (pp. 251-271). Washington, DC: Island Press.

Epley, N., Akalis, S., Waytz, A., \& Cacioppo, J. T. (2008). Creating social connection through inferential reproduction, loneliness, and perceived agency in gadgets, gods, and greyhounds. Psychological Science, 19, 114-120.

Epley, N., Waytz, A., \& Cacioppo, J. T. (2007). On seeing human: A three-factor theory of anthropomorphism. Psychological Review, 114, 864.

Erikson, P. (2000). The social significance of pet-keeping among Amazonian Indians. In A. Podberscek, E. S. Paul, \& J. A Serpell (Eds.) Companion animals and us: Exploring the relationships between people and pets (pp. 7-26). Cambridge, UK: Cambridge University Press.

Friedmann, E., Katcher, A., Lynch, J., \& Thomas, S. (1980). Animal companions and one-year survival of patients after discharge from a coronary care unit. Public Health Reports, 95, 307-312.

Ghirlanda, S., Acerbi, A., \& Herzog, H. (in press). A case study in media influence on choice: Dog movie stars and dog breed popularity. PloS ONE.

Ghirlanda, S., Acerbi, A., Herzog, H., \& Serpell, J. A. (2013). Fashion vs. function in cultural evolution: The case of dog breed popularity. PloS ONE, 8, e74770.

Gillum, R. F., \& Obisesan, T. O. (2010). Living with companion animals, physical activity and mortality in a US national cohort. International Journal of Environmental Research and Public Health, 7, 2452-2459. 
Glocker, M. L., Langleben, D. D., Ruparel, K., Loughead, J. W., Valdez, J. N., Griffin, M. D., ... Gur, R. C. (2009). Baby schema modulates the brain reward system in nulliparous women. Proceedings of the National Academy of Sciences, 106, 9115-9119.

Gould, S. J. (1979). Mickey Mouse meets Konrad Lorenz. Natural History, 88, 30-36.

Gray, P. B., \& Young, S. M. (2011). Human pet dynamics in cross-cultural perspective. Anthrozoös, 24, 17-30.

Grier, K. C. (1999). Childhood socialization and companion animals: United States, 1820-1870. Society and Animals, 7, 95-120.

Grier, K. C. (2006). Pets in America: A history. Chapel Hill, NC: UNC Press.

Gueguen, N., \& Ciccotti, S. (2008). Domestic dogs as facilitators in social interaction: An evaluation of helping and courtship behaviors. Anthrozoös. 21, 339-349.

Guthrie, S. (1995). Faces in the clouds. New York: Oxford University Press.

Hahn, M. W., \& Bentley, R. A. (2003). Drift as a mechanism for cultural change: An example from baby names. Proceedings of the Royal Society of London Series B: Biological Sciences, 270, S120-S123.

Hare, B., \& Tomasello, M. (2005). Human-like social skills in dogs?. Trends in Cognitive Sciences, 9, 439-444.

Hatkoff, I., Hatkoff, C., \& Kahumbu, D. P. (2006). Owen and Mzee. New York: Scholastic Press.

Hawkley, L. C., \& Cacioppo, J. T. (2010). How can I connect with thee: Measuring and comparing satisfaction in multiple relationship domains. Journal of Individual Psychology, 66, 43-67.

Headey, B. \& Grabka, M. (2011). Health correlates of pet ownership from national surveys. In P. McCardle, S. McCune, J. A. Griffin, \& V. Maholmes (Eds.), How animals affect us: Examining the influences of humananimal interaction on child development and human health. (pp. 153-162). Washington, DC: American Psychological Association.

Herzog, H. (2006). Forty-two thousand and one Dalmatians: Fads, social contagion, and dog breed popularity. Society and Animals, 14, 383-397.

Herzog, H. (2010). Some we love, some we hate, some we eat: Why it's so hard to think straight about animals. New York: Harper.

Herzog, H. (2011). The impact of pets on human health and psychological well-being fact, fiction, or hypothesis? Current Directions in Psychological Science, 20, 236-239.

Herzog, H. A., Bentley, R. A., \& Hahn, M. W. (2004). Random drift and large shifts in popularity of dog breeds. Proceedings of the Royal Society of London. Series B: Biological Sciences, 271, S353-S356.

Herzog, H. A., \& Elias, S. M. (2004). Effects of winning the Westminster Kennel Club dog show on breed popularity. Journal of the American Veterinary Medical Association, 225, 365-367.

Hirata, S., Yamakoshi, G., Fujita, S., Ohashi, G., \& Matsuzawa, T. (2001). Capturing and toying with hyraxes (Dendrohyrax dorsalis) by wild chimpanzees (Pan troglodytes) at Bossou, Guinea. American Journal of Primatology, 53, 93-97.

Holland, J. (2011). Unlikely friendships: 50 remarkable stories from the animal kingdom. New York: Workman Publishing.

Hsu, Y., \& Serpell, J. A. (2003). Development and validation of a questionnaire for measuring behavior and temperament traits in pet dogs. Journal of the American Veterinary Medical Association, 223, 1293-1300.

Izar, P., Verderane, M. P., Visalberghi, E., Ottoni, E. B., Gomes De Oliveira, M., Shirley, J., \& Fragaszy, D. (2006). Cross-genus adoption of a marmoset (Callithrix jacchus) by wild capuchin monkeys (Cebus libidinosus): Case report. American Journal of Primatology, 68, 692-700.

Kis, A., Bence, M., Lakatos, G., Pergel, E., Turcsán, B., Pluijmakers, J., \& Kubinyi, E. (2014). Oxytocin receptor gene polymorphisms are associated with human directed social behavior in dogs (Canis familiaris). PloS ONE, 9, e83993.

Knobel, D. L., Laurenson, M. K., Kazwala, R. R., Boden, L. A., \& Cleaveland, S. (2008). A cross-sectional study of factors associated with dog ownership in Tanzania. BMC Veterinary Research, 4, 1-10. doi: 10.1186/17466148-4-5.

Koivusilta, L. K., \& Ojanlatva, A. (2006). To have or not to have a pet for better health? PloS ONE, 1, e109.

Kuo, Z. Y. (1930). The genesis of the cat's response to the rat. Comparative Psychology, 11, 1-35.

Laurent, E. (2000). Children, "insects," and play in Japan. In A. Podberscek, E. S. Paul, \& J. A Serpell (Eds.) Companion animals and us: Exploring the relationships between people and pets (pp. 90-107). Cambridge, UK: Cambridge University Press.

Levine, G. N., Allen, K., Braun, L. T., Christian, H. E., Friedmann, E., Taubert, K. A., ...Lange, R. A. (2013). Pet ownership and cardiovascular risk: A scientific statement from the American Heart Association. Circulation, 127, 2353-2363. 
Lieberson, S. (2000). A matter of taste: How names, fashions, and culture change. New Haven, CT: Yale University Press.

Little, A. C. (2012). Manipulation of infant-like traits affects perceived cuteness of infant, adult and cat faces. Ethology, 118, 775-782.

LoBue, V. (2010). And along came a spider: Superior detection of spiders in children and adults. Journal of Experimental Child Psychology, 107, 59-66.

LoBue, V., Bloom Pickard, M., Sherman, K., Axford, C., \& DeLoache, J. S. (2013). British Journal of Developmental Psychology, 31, 57-69.

LoBue, V., \& DeLoache, J. S. (2010). Superior detection of threat-relevant stimuli in infancy. Developmental Science, 13, 221-228.

Mason, W. A., \& Kenny, M. (1974). Redirection of filial attachments in rhesus monkeys: Dogs as mother surrogates. Science, 183, 1209-1211.

Mesoudi, A. (2011). Cultural evolution: How Darwinian theory can explain human culture and synthesize the social sciences. Chicago: University of Chicago Press

Michel, J. B., Shen, Y. K., Aiden, A. P., Veres, A., Gray, M. K., Pickett, J. P., \& Aiden, E. L. (2011). Quantitative analysis of culture using millions of digitized books. Science, 331, 176-182.

Mithen, S. (1996). The prehistory of the mind: A search for the origins of art, religion and science. London: Thames \& Hudson.

Mueller, M. K. (2014). Is human-animal interaction (HAI) linked to positive youth development? Initial answers. Applied Developmental Science, 18, 5-16.

Müllersdorf, M., Granström, F., Sahlqvist, L., \& Tillgren, P. (2010). Aspects of health, physical/leisure activities, work and socio-demographics associated with pet ownership in Sweden. Scandinavian Journal of Public Health, 38, 53-63.

Nelson, X. J., \& Fijn, N. (2013). The use of visual media as a tool for investigating animal behaviour. Animal Behaviour, 85, 525-536.

New, J., Cosmides, L., \& Tooby, J. (2007). Category-specific attention for animals reflects ancestral priorities, not expertise. Proceedings of the National Academy of Sciences, 104, 16598-16603.

Parslow, R. A., Jorm, A. F., Christensen, H., \& Rodgers, B. (2005). Pet ownership and health in older adults: Findings from a survey of 2,551 community-based Australians aged 60-64. Gerontology, 51, 40-47.

Patronek, G. J., Slater, M., \& Marder, A. (2010). Use of a number-needed-to-ban calculation to illustrate limitations of breed-specific legislation in decreasing the risk of dog bite-related injury. Journal of the American Veterinary Medical Association, 237, 788-792.

Patterson, F., \& Cohn, R. H. (1985). Koko's kitten. New York: Scholastic.

Pickering, L. K., Marano, N., Bocchini, J. A., \& Angulo, F. J. (2008). Exposure to nontraditional pets at home and to animals in public settings: Risks to children. Pediatrics, 122, 876-886.

Pinker, S. (1997). How the mind works. New York: Norton.

Richerson, P. J., \& Boyd, R. (2008). Not by genes alone: How culture transformed human evolution. Chicago, IL: University of Chicago Press.

Ritvo, H. (1987). The emergence of modern pet keeping. Anthrozoös, 1, 158-165.

Sacks, J. J., Kresnow, M., \& Houston, B. (1996). Dog bites: How big a problem? Injury Prevention, 2, 52-54.

Serpell, J. A. (1987). Pet-keeping in non-Western societies: Some popular misconceptions. Anthrozoös, 1, 166-174.

Serpell, J. A. (1989). Pet-keeping and animal domestication: A reappraisal. In J. Clutton-Brock (Ed.) The walking larder: Patterns of domestication, pastorialism and predation (pp. 10-21). London: Unwin Hyman.

Serpell, J. (1996). In the company of animals: A study of human-animal relationships. New York: Cambridge University Press.

Serpell, J. A. (2003). Anthropomorphism and anthropomorphic selection: Beyond the" cute response." Society and Animals, 11, 83-100.

Serpell, J. A., \& Paul, E. S. (2011). Pets in the family: An evolutionary perspective. In C. A. Salmon and T. K. Shackelford (Eds.) The Oxford handbook of evolutionary family psychology (pp. 298-309). New York: Oxford University Press.

Shipman, P. (2010). The animal connection and human evolution. Current Anthropology, 51, 519-538.

Taylor, N., \& Signal, T. (2005). Empathy and attitudes to animals. Anthrozoös, 18, 18-27.

Thomas, K. (1984). Man and the natural world: Changing attitudes in England 1500-1800. London: Penguin.

Tifferet, S., Kruger, D. J., Bar-Lev, O., \& Zeller, S. (2013). Dog ownership increases attractiveness and attenuates perceptions of short-term mating strategy in cad-like men. Journal of Evolutionary Psychology, 11, 121129. 
Torrey, E. F., \& Yolken, R. H. (2005). Beasts of the earth: Animals, humans, and disease. New Brunswick, NJ: Rutgers University Press.

Waller, B. M., Peirce, K., Caeiro, C. C., Scheider, L., Burrows, A. M., McCune, S., \& Kaminski, J. (2013). Paedomorphic facial expressions give dogs a selective advantage. PloS One, 8(12), e82686.

Watanabe, M. (1974). The conception of nature in Japanese culture. Science, 183, 279-282.

Wells, D. L. (2009). The effects of animals on human health and well-being. Journal of Social Issues, 65, 523-543.

Westgarth, C., Heron, J., Ness, A. R., Bundred, P., Gaskell, R. M., Coyne, K. P., .. Dawson, S. (2010). Family pet ownership during childhood: Findings from a UK birth cohort and implications for public health research. International Journal of Environmental Research and Public Health, 7, 3704-3729.

Wilson, E. O. (1984). Biophilia. Cambridge, MA: Harvard University Press.

Wilson, E. O. (1993). Biophilia and the conservation ethic. In S. R. Kellert \& E. O. Wilson (Eds.) The biophilia hypothesis (pp. 31-41). Washington, DC: Island Press. 